\title{
The Impact of Power Outages on Small Businesses in the City of Johannesburg
}

\author{
T. Schoeman and M. Saunders
}

\begin{abstract}
Although load shedding is mostly something of the past, ageing infrastructure, lack of maintenance and cable theft cause almost daily power outages in the City of Johannesburg (CoJ). It is especially the north western parts of CoJ that have a high incidence of power outages that impact small businesses. This study investigated the impacts and costs of power outages on small businesses in six shopping centers located in the north western parts of CoJ. More than two thirds of the businesses stated that they experience, on average, one to three power outages during a month whereas 18.5 per cent stated that they experience between four and seven power outages during a month. Businesses indicated that they have less customers and that they made less income during a day with a power outage. To cope with the impact power outages most businesses have back-up power that adds to the running cost of the business.
\end{abstract}

Keywords - Back-up power, City of Johannesburg, power outage, small businesses.

\section{INTRODUCTION}

South Africa encountered several problems in its energy sector over the past decade. Not only was there an increase in price of electricity, but often there were shortages in energy supply that lead to the implementation of load shedding. Load shedding was introduced in South Africa during 2008 due to the shortage in electricity produced by Eskom [1]. Many businesses spent large amounts of money on back-up power measures such as generators, which these businesses still possess. Although these back-up measures are not used for load shedding anymore, many businesses would not have these measures if not for load shedding. Although load shedding is mostly something of the past, there are still many power outages within the Johannesburg area that have a large impact on both residential and commercial sectors. The effect of these power outages on businesses in Johannesburg has not been fully explored, despite the impact it has. Not only can some businesses not operate during power outages, but there are additional costs as well. These costs may be due to back-up power devices bought to mitigate power loss and small businesses are more likely to suffer due to the additional costs and less customers. It is small businesses that suffer the most during power outages, especially those in

T. Schoeman is a lecturer in the Department of Geography, Environmental Management \& Energy Studies, University of Johannesburg, South Africa.

M. Saunders was post-graduate student in the same department at the University of Johannesburg. He is now with Southern Mapping, Johannesburg, South Africa . low-income suburbs where these businesses are without the means to install back-up generators.

The definition of a power outage is when the supply of electricity is stopped, leading to no power being provided to the consumer [,], [3]. There are two types of power outages: planned and unplanned outages. A planned outage is a power interruption that occurs when the power is switched off at a substation or other area within the local grid, so that maintenance can be performed, or emergency repairs can take place [4]. Unplanned outages are periods of time when the electricity supply to a particular building or area is interrupted and is not scheduled. Unplanned outages can occur due to cable theft, weather conditions, illegal electricity connections, old infrastructure, and even excavation or building developments [5], [6]. Electricity is a vital resource in the $21^{\text {st }}$ century [7] and affect both residential and industrial consumers if it is not available. In the literature the costs due to damages caused by power outages are known as Value of Lost Load (VoLL) and because of the diversity of potential effects, calculating the VoLL poses a huge challenge for researchers [8].

\section{THE INTERNATIONAL SCENE}

Power outages are an international phenomenon and the causes of these power outages differs amongst different countries. In Sweden 'nature has been the number one enemy against the supply of security of the electricity' [9]. The economic damage of one single storm, the Gudrun storm of 2005, was calculated around 3 billion euros [9]. Reference [10] emphasize that like other countries the cost of power outages in Sweden depends on the time and what day of the week it occurs. Industries will incur high costs if the outage is in the middle of a working day, while households would incur very small or even no costs. This was also the finding of a study of Ireland where VoLLs to industry is the highest on midweek days between $8 \mathrm{am}$ and $6 \mathrm{pm}$, and that it can be as high as $€ 17$ million per hour [11]. The authors further emphasized that the VoLL in Ireland has increased between 2001 and 2008 and that it is higher than what the regulator authorities assumes it to be.

In their study of VoLLs in Germany, [8] identified a North-South divide in the vulnerability of German counties, with counties in the south tending to face larger losses. For businesses they calculated the national VoLLs for construction companies to be $118.15 € / \mathrm{kWh}$ (kilowatt hour) and 10.16 $€ / \mathrm{kWh}$ for service companies [8]. An economic assessment of a simulated 12-hour power outage in Austria calculated the VoLLs for the wholesale and retail trade at $39.9 € / \mathrm{kWh}$, food service activities at $12.2 € / \mathrm{kWh}$, information and 
communication services at $15.5 € / \mathrm{kWh}$ and administrative and support service activities at $13.4 € / \mathrm{kWh}[12]$.

\section{Sub-SAHARAN Africa AND SOUTH AFrica}

Reference [13] investigated power outages and firm performance in Sub-Saharan Africa and stated that the relatively poor state of the electricity network causes considerable disruption to the power supply of many large African cities. They found that frequent and unplanned power outages represent a significant burden on African firms, especially small firms that have lower total sales compared to medium sized firms during power outages. Estimates shows that if the average hours of outage are reduced to that of the average of South Africa, firms without generators can show an increase of sales of 83 per cent [13].

A study conducted on Africa's power infrastructure stated that Sub-Saharan Africa's "power generation capacity is lower than that of any other world region, and capacity growth has stagnated compared with other developing regions" [14,1]. They have estimated that the total sales of African firms to be 4.9 per cent lower if the electricity supplies were dependable. Losses due to power outages were estimated to be as much as six per cent of turnover for businesses in the formal sector and 16 per cent for businesses in the informal sector that lack back-up power sources [15].

Reference [16] calculated the direct Cost of Unserved Energy (COUE) for South Africa for 2013. For the trade sector they calculated the gross value added (GVA)/kWh to be R101.26, for transport and communication R76.52, finance R93.28 and for community services R147.94 GVA/kWh. In South Africa the Government's IRP2010 policy reported the COUE as R75/kWh [17]. Just like in Ireland [11], the South African regulatory authority underestimates the cost of power outages to consumers.

\section{Power Outages In JohanNesburg}

A study was conducted in the $\mathrm{CoJ}$ in 2016, focusing on power outages within the area. It collected reports of power outages (both unplanned and planned) which were announced by social media accounts owned by City Power, the CoJ's electricity utility [18]. These announcements were made to inform customers about both planned and unplanned power outages. Over a period of 4 weeks during March and April there were 300 reported power failures, spread across 174 different areas, which can be seen in Fig. 1. It is especially the western and north western parts of Johannesburg that experience the highest number of power outages. The results of the study showed that an average of 11 outages were experienced per a day. On certain days during the study, at least 20 areas within Johannesburg experienced a power outage. Some of these outages took over 72 hours to resolve, which led to smaller businesses being affected, especially those which deal with goods that expire due to lack of refrigeration. These details were backed up by City Power, who stated that they had experienced five low voltage faults per a day, and two medium voltage faults per a week [18]. Low voltage vaults result in a street or road in losing electricity, while medium voltage faults can result in a whole suburb from losing power.

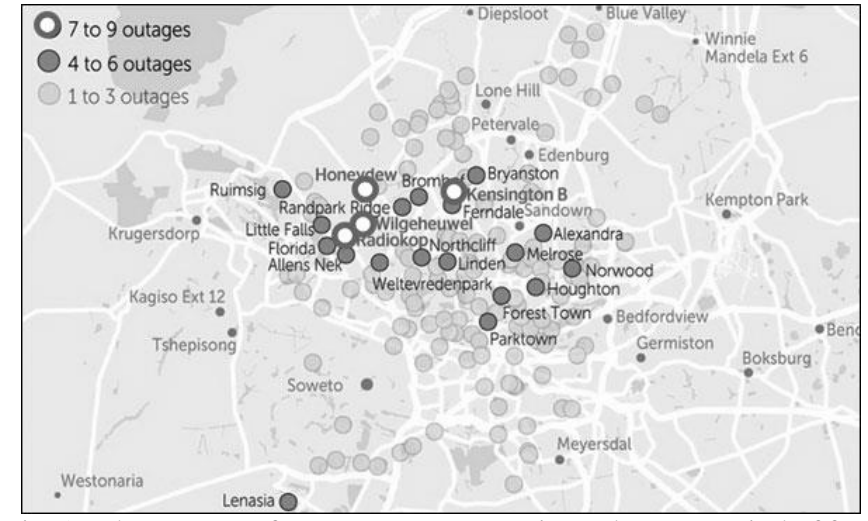

Fig. 1: The amount of power outages experienced over a period of four weeks during March and April 2016 [18]

There are numerous instances where residents and business were 'left in the dark' due to power outages. One of the most severe unplanned outages occurred in September 2017 where parts in the inner city of Johannesburg was without power for 11 days due to cable theft [19]. This had a severe impact on businesses - not only was there a huge loss in income and clients, but produce that required refrigeration had to be thrown away and extra expenses were occurred such as the hiring of security guards as 'thieves took advantage of the lights being out' and fuel to run generators [20]. Once of the most recent planned outages was announced by City Power in April 2018. City Power informed residents that due to stolen cables, large parts of the suburbs of Northcliff and Roodepoort will only be supplied with electricity at four-hour intervals for a period of 14 days. A cable that links two substations was stolen and this resulted in major damage to transformers [21]. It was estimated to take at least 14 days to replace the damaged transformers and stolen cables.

Cable theft, aging infrastructure and the previous administration are main reasons given for the power outages. The City Power spokesperson said that more than 100 outages occur around the city every month and stated that 45 per cent were due to cable theft [22]. The Member of the Mayoral Committee for Environment and Infrastructure Services of the CoJ stated that there is a R69 billion development and maintenance backlog of the electricity infrastructure in the CoJ [23]. The Mayor of the CoJ stated in November 2017 that when his administration came into power in August 2016, they 'inherited' an electricity infrastructure where 27 per cent of the infrastrucutre is past its life span. He further gave an example of a sub-station that supplies the entire inner city of Johannesburg that is 75 years old, 30 years past its useful lifespan and for which no service parts are availabe as the supplier stopped making the parts 20 years ago [24]. This study therefore investigated the impacts of power outages on small businesses within the City of Johannesburg, concentrating on the north western parts of the city. It further aimed to determine what measures are used by these businesses to mitigate power outages.

\section{Methodology}

Small businesses in six shopping centres were asked to 
complete a structured questionnaire after obtaining informed consent from either the owner or manager of a business. The shopping centres were chosen according to the frequency of power outages experienced based on the study conducted by [18]. These shopping centres are all located in the north western parts of Johannesburg as this is the area with the highest incidence of power outages (see Fig. 1).

The first part of the questionnaire covered general business information such as type of business, number of employees and what the respondent identified as the single biggest consumer of eletricity in their business. The next set of questions covered the frequency and duration of power outages. The questions then moved to the impact on the business in terms of the amount of customers, whether or not a loss of income was experienced and if damages to equipment occurred due to power outages. The final section contained questions about back-up power measures and the cost involved in using these measures. Not all small business in these shopping centres were willing to participate in the study. A number of businesses declined to participate due to the income-related questions in the questionnaire. Other businesses indicated that they do not have the time to participate in the survey. A total of 54 businesses completed the questionnaire and the results are discuss in the next section.

\section{RESULTS AND DISCUSSION}

\section{A. Business information}

The businesses that completed the questionnaire varied in nature ranging from pet stores, pharmacies, restaurants to drycleaners. Of these 54 businesses, 27.7 per cent are part of a franchise. Often it is a requirement of the franchise to have a source of back-up power as it is part of an established enterprise and is expected to cater for customers regardless of power loss. The number of employees found at a business can be a good indication of the size of the business. The results showed that 51.9 per cent of the businesses have between one and five employees, 33.3 per cent between six and 10 employees, with 14.8 per cent of businesses between 11 and 20 employees.

Eighty-seven per cent of the businesses stated that they do monitor the electricity usage of their business, with some commenting that it was due to the risk of power outages and increasing electricity prices. When asked what the biggest, single consumer of electricity is within the business, the answers varied. However, there were two options which stood out against the rest. The first was heating and cooling systems. The second highest user of electricity was put down to business equipment. This answer was given by a variety of businesses, from drycleaners and hair salons, to photography and copying shops. The amount of energy used for some of these appliances is quite high, for example, a washing machine use between 1 200 and 3000 watts, and a kettle use between 2200 and 3000 watts. This highlights the importance of electricity within many of these businesses, where electricity is essential for their operation. The third biggest consumer of electricity was refrigerators for business use. Restaurants indicated the need of large refrigerators to preserve food. Pharmacies also commented on the high usage of refrigerators with regards to preserving certain medicine but stated that heating and cooling systems were still the biggest consumer within the business. The last notable choice was that of lighting, especially within smaller businesses (in physical size), some of which did not have the need for heating or cooling systems.

\section{B. Frequency and duration of power outages}

The majority $(90.7 \%)$ of the businesses interviewed stated that electricity is essential for the operation of the business. The remaining 9.3 per cent were made up of a spice shop, boutique clothing store, two phone repair shops and a cable TV installation business. The first four stated that an invoice could be written up and any sale of stock could be added to the business' inventory once power had been restored. The TV installation business indicated that it is more important to have electricity at the building they install the cable TV than at their shop. They further commented that often they must reschedule an installation when there is not electricity available at the place of installation. This results in extra costs for them.

Certain businesses commented on why electricity was so essential. Pharmacies need electricity to run computer systems controlling stock, as well as the refrigerators necessary to keep certain medicines from expiring. Pet stores stated that certain stock they have may die, such as reptiles which require UV light to survive in captivity, as well as circulation of air in fish tanks. Restaurants indicated the importance of power supply regarding the refrigeration of stock. The food stored in these refrigerators could expire, which would be costly in both the loss of stock, the money spent to replace this stock and the inability to serve customers as limited/no food is available for use.

The frequency of power loss is also an important factor within this study. More than two thirds $(68.5 \%)$ of the businesses stated that they experience, on average, one to three power outages during a month (Fig. 2). Another 18.5 per cent stated that they experience between four and seven power outages during a month. Nine out of the ten business who stated that power outages usually do not occur were situated in centers where the shopping center provides back-up power as soon as an outage occurs. Due to this, some of these business owners stated that although a power outage may occur, they may not be aware of it due to the speed in which the back-up power starts up. The responses are a clear indication that power outages occur on a 'regular' basis for most small businesses and that back-up measures can be considered as a necessity to run their business.

\section{Frequency of power outages}

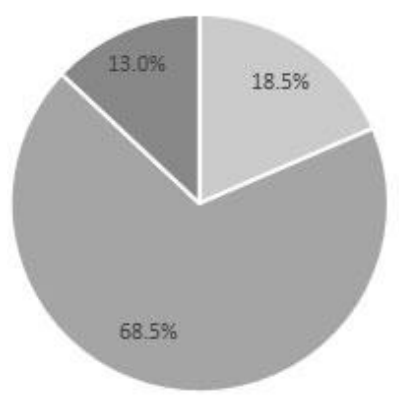

- Usually does not occur = 1-3 times a month - 4-7 times a month

Fig. 2: Frequency of power outages experienced in a month 
The duration of the power outage is also an important factor to consider. Although this may have less of an effect on businesses that use back-up power supplied by the center, the impact on other businesses is clear. Some businesses make use of generators as back-up power supplies, which require either petrol or diesel fuel in order to run. The longer the power outage, the more fuel is needed to keep the generator running. As stated before, [16] calculated the COUE to be between R76.25 to $147.94 \mathrm{GVA} / \mathrm{kWh}$ for various commercial sectors. The length of the outage may also lead to traffic build-up in the surrounding areas, which were commented on by interviewees. The amount of traffic can lead to a loss in customers, regardless of whether or not the business has back-up power.

Fig. 3 shows that businesses within the suburbs of Randpark Ridge and Northwold are affected greatly by power outages (Northwold, SPAR Centre and Trinity Village shopping centers). Almost a quarter (22.2\%) of businesses experienced power outages lasting between four and seven hours long in these two suburbs. Although 7.4 per cent businesses located in Bryanston and Douglasdale experienced outages of similar a time length, the power outages appear to be shorter in length. Most of the businesses in this area experienced power outages between one and three hours long.

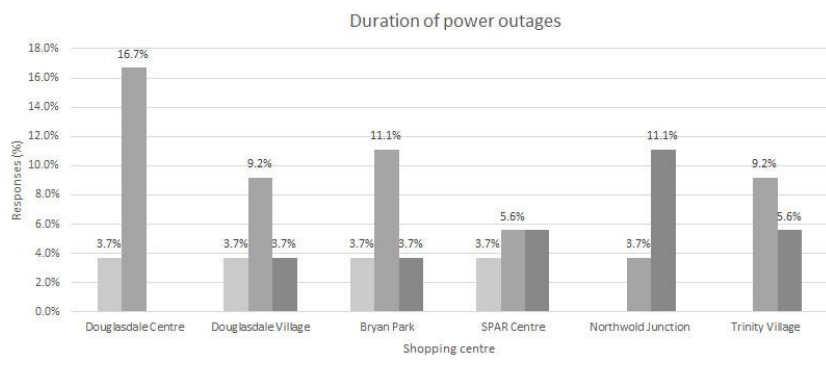

Fig. 3: The duration of power outages in the shopping centers

The majority $(92.6 \%)$ of businesses stated that the most recent power outage had occurred within the past month (Fig. 4). Although 20.4 per cent of all businesses stated that it had been between three and four weeks since an outage, the problems of electricity supply can still be seen. Another 20.4 per cent of businesses said that their most recent outage occurred between two to three weeks ago. Just over half (51.9\%) of the businesses stated that they had experienced a power outage during the week before the questionnaire was received.

\section{Last time of a power outage}

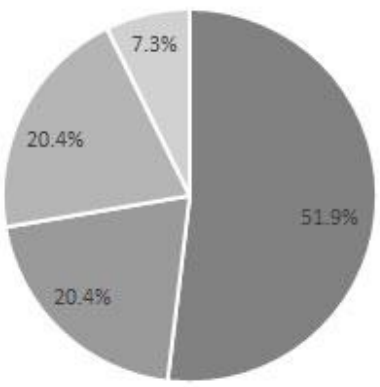

- During the past week

- 2-3 weeks ago

- 3-4 weeks ago

" Morethan a month ago

Fig. 4: The last time businesses experienced a power outage

\section{Impacts of power outages on businesses}

When asked how power loss effected the number of customers experienced on a day with a power outage in comparison to an average day with no power loss, 44.4 per cent of businesses stated that no notable difference occurs (Fig. 5). However, it must be noted that these were mostly in a shopping center with back-up power supplied by the center. Less customers on a day with a power outage was recorded by 38.9 per cent of the businesses. These were mostly businesses that made use of privately-owned back-up measures. Respondents in Trinity Village, Bryan Park and Douglasdale Village shopping centers stated that power outages led to a high amount of traffic congestion in the area, which results in less customers being able to get to their business. These shopping centers are located on major roads and during a power outage traffic lights do not operate. This results in significant built-up of traffic along these roads and less customers for businesses in these shopping centers.

\section{Effect on number of customers}

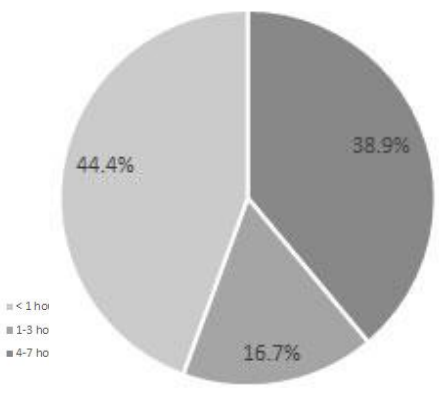

- Less customers

- Morecustomers

" No notable difference

Fig. 5: Effect of power outages on the number of customers

The 16.7 per cent of businesses that experienced more customers than usual during power outages are restaurants who stated that the people living in the area tended to eat out during periods of power outages. Three of these restaurants stated that they have at least 30 per cent more customers than usual during a power outage. This change in customers affects the amount of income generated by these businesses. The income discussed within this study is the amount of gross profit generated during the course of one day. This allows for the comparison between a normal day's income and income generated on a day when a power outage occurs. 42.6 per cent of businesses stated that they made less income during a day with a power outage, while 40.7 per cent found there to be no notable difference. The nine businesses which had an increase in customers (Fig. 5) are restaurants and generated more income than on an average day. These restaurants experienced up to 60 per cent more income than usual on days with a power outage. Three restaurants disclosed the amount of income generated on these days and stated an increase of between R5 000 and R10 000 in income. Although many businesses preferred not to disclose the amount lost or gained compared to an average day, 27.8 per cent of businesses stated that they lost between R1 000 and R10 000 in comparison to an average day. This loss in income is extremely detrimental to these smaller businesses, which some of these businesses highlighted. 
Another way in which power loss can affected businesses, is the damage to equipment caused by power outages, and other power-related problems such as power surges when the electricity comes back on. Twenty (37\%) of businesses experienced damages due to power outages. Fourteen of the 20 businesses experienced damages costing R5 000 or less. Some businesses, such as a photography shop, had damages valued at R50 000 due to a specialist printer being damaged. Although these businesses were insured, money is lost in the inability of the business to operate effectively until the damaged equipment is replaced.

\section{Back-up power sources}

The last section of the questionnaire investigated the use of back-up power sources. Out of the 54 businesses 87 per cent make use of back-up power during power outages. The remaining 13 per cent of businesses felt that they were too small in size to justify the use of back-up power sources due to the expense involved. The use of back-up power sources in the north western parts of Johannesburg differs significantly from the study conducted by [25] in Cape Town where only 13 per cent of the commercial sample of their study had a back-up power source. Eighty-three per cent of the businesses in Johannesburg that have back-up power stated that these measures were put in place to mitigate load shedding that was prevalent between 2008 and 2015. In the [26] study, more than 50 per cent of the generators were installed between 2008 and 2009 in Cape Town. The results show that more businesses in Johannesburg installed back-up power sources during the 'height' of load shedding than their counterparts in Cape Town.

For 57.4 per cent of businesses the shopping center provides the back-up power, while 42.6 per cent have privately-owned back-up power or no back-up measures. Interesting to note that some shopping centers have strict regulations regarding the use of back-up power. An example was given of a shopping center where originally no rules regarding the use of back-up measures were in place. This changed when one business refilled its generator whilst it was still running. The generator then caught on fire. After this incident, rules were put in place, where each business had to be assessed by center management. The management assessed whether a generator was essential for the business, and if it was required, the installation had to be overseen to ensure safety. Three shopping centers do not allow for the installation of privately-owned measures as the centers provides back-up power.

All these businesses pay a monthly fee for the service of having back-up power provided by the center. This fee is included into the monthly rental costs charged by the center, regardless of whether power outages occurred. The service fee varies according to the physical size of the business, or according to how much electricity the business requires to operate. Certain businesses had a higher fee, such as a laundromat which paid R500 per month, compared to a travel agency that paid R300 per month for back-up power. Fig. 6 shows that amount added to the monthly rental in the three shopping centers that provide back-up power. The highest amount paid extra per month was R1 000 and in Trinity Village, which is the shopping center that recorded the most power outages. Most of the businesses interviewed stated that they do not have a problem with this monthly fee, as the back-up power is efficient and reliable. It also removes the need to buy and install privately-owned measures, which need to be maintained regularly and that leads to more expenses.

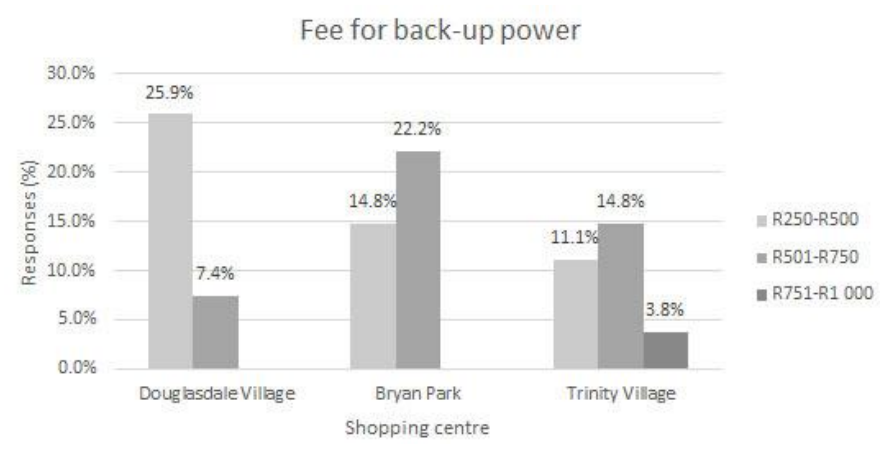

Fig. 6: Amount per month for center provided back-up power

Different back-up measures are used by businesses in the three shopping centers that do not provide back-up power. Generators are the most popular measure at 44.4 per cent. Larger businesses mostly used these due to the cost involved in buying and running generators. Inverters and batteries are used by 37 per cent, while uninterrupted power supplies (UPS) by 14.8 per cent of businesses. Only one business, a restaurant, uses a gas stove. Another restaurant stated that they only require back-up power for the cash register, as they make use of a wood-burning oven for pizzas. Other items on their menu are not available during a power outage.

Sixty-five per cent of businesses that make use of privately-owned back-up measures spent between R5 000 and R10 000, 20 per cent have spent between R10 000 and R15 000 and 15 per cent spent more than R15 000. This relates with the popularity of generators amongst these businesses as a back-up measure. Some of these measures, such as generators, have operating expenses due to the fuel required to run it and maintenance. Thirty-five per cent of the businesses indicated that on average they spend under R250 per month on running back-up measures. The majority (55\%) spend between R250 and R750 per month while 10 per cent spend more than R1 000 per month.

\section{CONCLUSION}

Power outages frequently occur in the Johannesburg area and can be of such a long duration that a whole business day is lost. This has a significant impact on small businesses and can be considered as a regular occurrence that needs to be dealt with in the running of a business. Dealing with power outages adds to the running cost of a business. In shopping centers that provide back-up power measures, the small business must pay more per month for this service. If such as service is not provided, the business must spend money on buying a back-up power source and also spend money on running and maintaining such back-up measure. Further costs to a business may result from equipment damaged due to power surges and stock that needs to be replaced. Not only does power outages increase the running cost of businesses, but 42.6 per cent recorded a reduction in income on days with power outages. Only restaurants showed an increase in 
customers as more people eat out or get take-aways during power outages.

In South Africa, small, medium and micro-enterprises (SMMEs) represents 40 per cent of all business and contributes 36 per cent to the economy [26]. The National Development Plan forecasts that by 2030, 90 per cent of all new jobs in South Africa will be in SMMEs [28]. For small business to increase their contribution to the local economy and create more jobs, and enabling environment is needed. However, the frequent power outages in the city that is considered the economic hub of South Africa, is threatening small businesses and can have a detrimental effect on growth in this sector of the economy.

\section{REFERENCES}

[1] R. Inglesi, "Aggregate electricity demand in South Africa: Conditional forecasts to 2030," Applied Energy, vol. 87, no. 1, pp. 197-204, January 2010. https://doi.org/10.1016/ j.apenergy.2009.08.017

[2] M. De Nooij, C. Koopmans, and C. Bijvoet, "The value of supply security: The costs of power interruptions: Economic input for damage reduction and investment in networks," Energy Economics, vol. 29, no. 2, pp.277-295, March 2007. https://doi.org/10.1016/j.eneco.2006.05.022

[3] C. Growitsch, R. Malischek, S. Nick and H. Wetzel, The costs of power interruptions in Germany: An assessment in the light of the Energiewende, EWI Working Papers 2013-7, Energiewirtschaftliches Institut an der Universitaet zu Koeln (EWI), 2013. Available: http://www.ewi.uni-koeln.de/

fileadmin/user_upload/Publikationen/Working_Paper/EWI_WP_13-07_ Costs_of_Power_Interruptions_in__Germany.pdf

[4] City Power, "Planned outages," 2018. Available: https://www.citypower.co.za/Pages/Planned-Outages.aspx

[5] S.R. Han, S.D. Guikema, and S.M. Quiring, "Improving the predictive accuracy of hurricane power outage forecasts using generalized additive models," Risk Analysis, vol. 29, no. 10, pp. 1443-1453, September 2009. https://doi.org/10.1111/ j.1539-6924.2009.01280.x

[6] R. Nateghi, S.D. Guikema, and S.M. Quiring, "Comparison and validation of statistical methods for predicting power outage durations in the event of hurricanes," Risk Analysis, vol. 31, no. 12, pp. 1897-1906, April 2011. https://doi: 10.1111/ j.1539-6924.2011.01618.x

[7] A.J. Praktiknjo, A. Hähnel, and G. Erdman, "Assessing energy supply security: Outage costs in private households," Energy Policy, vol. 39, no. 12 , pp. 7825-33, December 2011. https:// doi.org/10.1016/j.enpol.2011.09.028

[8] A. Wolf, and L. Wenzel, "Regional diversity in the costs of electricity outages: Results for German counties," Utilities Policy, vol. 43 no. B, pp. 195-205, December 2016. https://doi.org/10.1016/j.jup.2014.08.004

[9] N. Gündüz, S. Küfeoğly and M. Lehtonen, "Impacts of natural disasters on Swedish electric power policy: A case study," Sustainability, vol. 9, no. 2, pp. 230, February 2017. https://doi.org/10.3390/su9020230

[10] F. Carlsson and P. Martinsson, "Does it matter when a power outage occurs? A choice experiment study on the willingness to pay to avoid power outages," Energy Economic, vol. 30, no. 3, pp. 1232-45, May 2008. https://doi.org/10.1016/ j.eneco.2007.04.001

[11] E. Leahy and R.S.J. Tol, "An estimate of the value of lost load for Ireland," Energy Policy, vol. 39, no. 3, pp. 1514-20, March 2011. https://doi.org/10.1016/j.enpol.2010.12.025

[12] J. Reichl, M. Schmidthaler and F. Schneider, "The value of supply security: The costs of power outages to Austrian households, firms and the public sector," Energy Economics, vol. 36, no. C, pp. 256-261, March 2013. https://doi.org/ 10.1016/j.eneco.2012.08.044

[13] M.A. Cole, R.J.R. Elliot, G. Occhiali, and E. Strobl, "Power outages and firm performance in Sub-Saharan Africa," Journal of Development Economics, vol. 134, $\quad$ September 2018. https://doi.org/10.1016/j.jdeveco.2018.05.003G.

[14] A. Eberhard, O. Rosnes, M. Shkaratan, and H. Vennemo, Africa's power infrastructure: Investment, integration, efficiency, Directions in Development: Infrastructure, Washington DC: World Bank, 2011, pp. $1-12$. https://doi.org/10.1596/978-0-8213-8455-8

Available: https://openknowledge.worldbank.org/handle/10986/2290

[15] V. Foster and J. Steinbuks, Paying the price for unreliable power supplies: In-house generation of electricity firms in Africa, Working Paper 2, Africa Infrastructure Country Diagnostic, Washington DC: World Bank, $2009 . \quad$ Available: https://openknowledge.worldbank.org/handle/10986/4116

[16] U.J. Minnaar, W. Visser and J. Crafford, "An economic model for the cost of electricity service interruption in South Africa," Utilities Policy, vol. 48, no. C, pp. 41-50, October 2017. https://doi.org/10.1016/j.jup.2017.08.010

[17] Department of Energy, "Integrated Resource Plan 2010: Cost of Unserved Energy (COUE) - IRP 2010 input parameter information sheet (supply input)," 2010. Available: http://www.energy.gov.za/

[18] P. Anetos, "Left in the dark: Johannesburg suffers 11 power failures a day," Times Live, 6 May 2016. Available: https://web.archive.org/web/20160917015717/http:/www.timeslive.co.z a:80/sundaytimes/stnews/2016/05/06/Left-in-the-dark-Johannesburg-suf fers-11-power-failures-a-day

[19] P. Dlamini, "Power finally restored in Joburg city centre," Time Live, 14 September 2017. Available: https://www.timeslive .co.za/news/south-africa/2017-09-14-power-finally-restored-in-joburg-ci ty-centre/

[20] N. Jordaan and K. Masweneng, "Residents and business suffering due to power outages in Joburg CBD," Times Live, 11 September 2017. Available: https://www.timeslive.co.za/news/ south-africa/2017-09-11-residents-and-business-suffering-due-to-power -outages-in-joburg-cbd/

[21] A. McGill, "Must read: 4-hour power rotation for Northcliff and Roodepoort for next 14 days," Northcliff Melville Times, 14 April 2018. Available: https://northcliffmelvilletimes.co.za/ 270843/must-read-4-hour-power-rotation-northcliff-roodepoort-next-14days/

[22] S. Kretzmann, "Small Jo'burg businesses left in the dark," GroundUp, 22 May 2017. Available: https://www.groundup. org.za/article/small-joburg-businesses-left-dark/

[23] CoJ (City of Johannesburg), "City Power goes hi-tech to put a stop to power outages," 15 June $2017 . \quad$ Available: https://www.joburg.org.za/media_/Newsroom/Pages/2017\%20Articles/ City-Power-goes-hi-tech-to-put-a-stop-to-power-outages.aspx

[24] H. Mashaba, "The true state of infrastructure challenges in the City of Johannesburg," Speech delivered by Mayor Herman Mashaba at a press conference on the state of Johannesburg's infrastructure, held at the City Council Chambers, 7 November $2017 . \quad$ Available: http://www.ward23jhbsouth.co.za/ attachments/true-state-of-infrastructure.pdf

[25] O. Dzobo, T. Gaunt and R. Herman, "Reliability worth assessment of electricity consumers: A South African case study" Journal of Energy in Southern Africa, vol. 23, no. 3, pp. 31-39, August 2012. Available: http://www.scielo.org.za/ pdf/jesa/v23n3/05.pdf

[26] GEM (Global Entrepreneurship Monitor), Global Entrepreneurship Monitor: Global report 2016/17, 2017, pp. 92. Available: http://www.gemconsortium.org/report/49812

[27] National Planning Commission, National Development Plan 2030: Our future - make it work, 2012. Available from: https://www.gov.za/sites/default/files/NDP-2030-Our-future-make-it-wo rk_r.pdf 